Document downloaded from:

http://hdl.handle.net/10251/141958

This paper must be cited as:

Quiles-Carrillo, L.; Montanes, N.; Jorda-Vilaplana, A.; Balart, R.; Torres-Giner, S. (04-2). A comparative study on the effect of different reactive compatibilizers on injection-molded pieces of bio-based high-density polyethylene/polylactide blends. Journal of Applied Polymer Science. 136(16). https://doi.org/10.1002/APP.47396

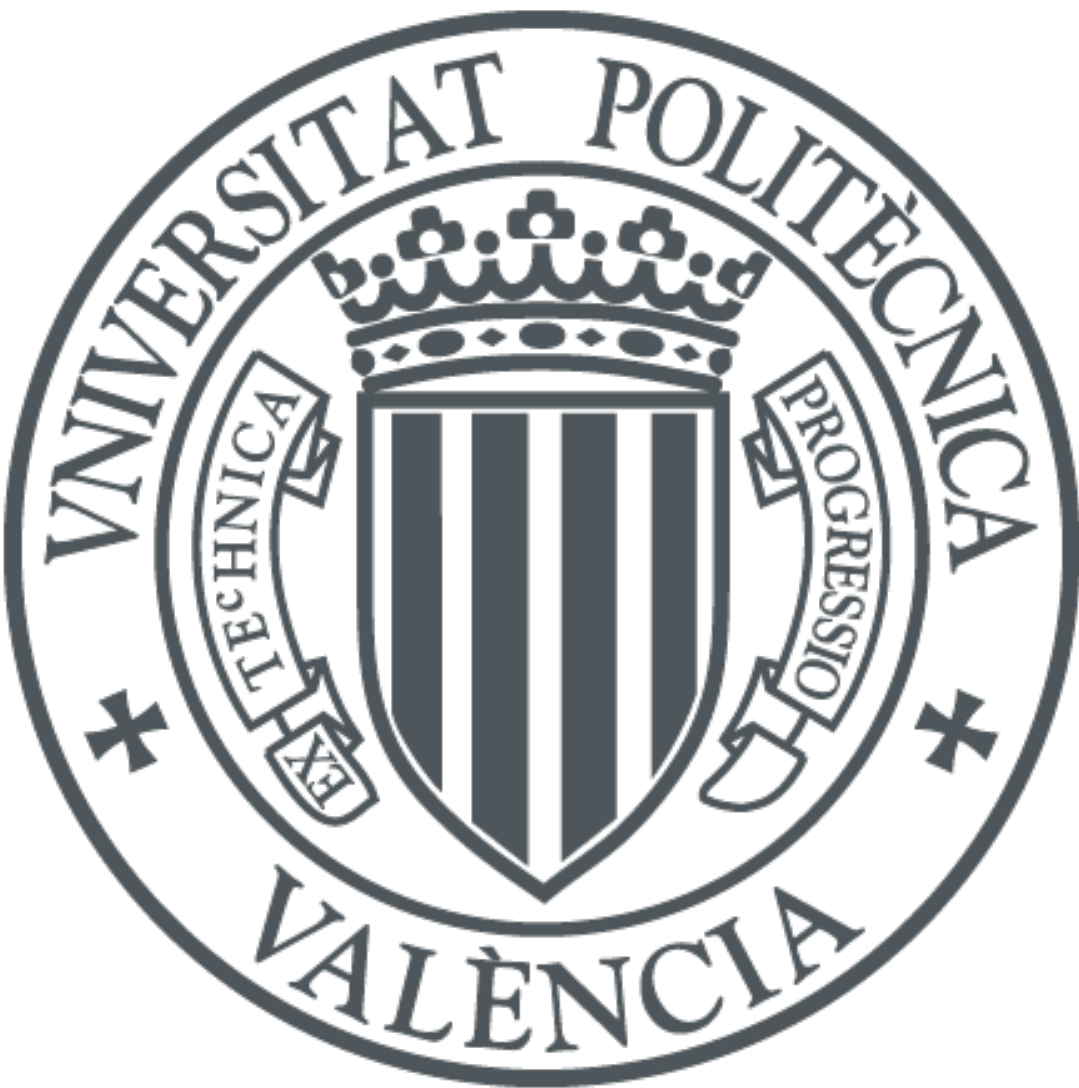

The final publication is available at

https://doi.org/10.1002/APP.47396

Copyright John Wiley \& Sons

Additional Information

"This is the peer reviewed version of the following article:

Quiles\&\#8208;Carrillo, L., Montanes, N., Jorda\&\#8208;Vilaplana, A., Balart, R., \& Torres\&\#8208;Giner, S. (2019). A comparative study on the effect of different reactive compatibilizers on injection\&\#8208;molded pieces of bio\&\#8208;based high\&\#8208;density polyethylene/polylactide blends. Journal of Applied Polymer Science, 136(16), 47396, which has been published in final form at https://doi.org/10.1002/APP.47396. This article may be used for non-commercial purposes in accordance with Wiley Terms and Conditions for Self- 


\title{
A comparative study on the effect of different reactive compatibilizers on injection-molded pieces of bio-based high-density polyethylene/polylactide blends
}

\author{
L. Quiles-Carrillo1, N. Montanes ${ }^{1}$, A. Jorda-Vilaplana ${ }^{1 *}$, R. Balart ${ }^{1}$, S. Torres-Giner ${ }^{1,2}$ \\ (1) Technological Institute of Materials (ITM), Universitat Politècnica de València, \\ Plaza Ferrándiz y Carbonell s/n, Alcoy 03801, Spain \\ *Corresponding author: amjorvi@upv.es
}

(2) Novel Materials and Nanotechnology Group, Institute of Agrochemistry and Food Technology (IATA), Spanish Council for Scientific Research (CSIC), Avenida Agustín Escardino 7, Paterna 46980, Spain

Abstract. The present study reports on the development of binary blends consisting of bio-based high-density polyethylene (bio-HDPE) with polylactide (PLA), in the 5-20 $\mathrm{w} t \%$ range, prepared by melt compounding and then shaped into pieces by injection molding. In order to enhance the miscibility between the green polyolefin and the biopolyester, different reactive compatibilizers were added during the melt blending process, namely polyethylene-grafted maleic anhydride (PE-g-MA), poly(ethylene-coglycidyl methacrylate) (PE-co-GMA), maleinized linseed oil (MLO), and a combination of MLO with dicumyl peroxide (DCP). Among the tested compatibilizers, the dual addition of MLO and DCP provided the binary blend pieces with the most balanced mechanical performance in terms of rigidity and impact strength as well as the highest thermal stability. The fracture surface of the binary blend piece processed with MLO and DCP revealed the formation of a continuous structure in which the dispersed PLA phase was nearly no discerned in the bio-HDPE matrix. The resultant miscibility improvement was ascribed to both the high solubility and plasticizing effect of MLO on the PLA phase as well as the cross-linking effect of DCP on both biopolymers. The latter effect was particularly related to the formation of macroradicals of each biopolymer that, thereafter, led to the in situ formation of bio-HDPE-co-PLA copolymers and also to the development of a partially cross-linked network in the binary blend. As a result, cost-effective and fully bio-based polymer pieces with improved mechanical strength, high toughness, and enhanced thermal resistance were obtained.

Keywords: Green polyolefins, PLA, reactive extrusion, multi-functionalized vegetable oils, peroxides, mechanical properties 


\section{INTRODUCTION}

Current awareness of environmental issues related to the extensive use of plastics and the increasing necessity of reducing the carbon footprint is generating a great interest in the use of polymer materials derived from natural resources and with great capacity to be recycled. This trend has significantly raised both the interest and use of bio-based and biodegradable polymers, which are capable of decomposing in composting conditions and show similar technical characteristics than their fossil-derived counterparts. ${ }^{1}$ Although the price and performance of most biopolymers are still far to those of petrochemical polymers, ${ }^{2}$ the development of either green composites ${ }^{3,4}$ or biopolymer blends 5,6 can certainly contribute to promote the use of biopolymers at industrial scale.

The use of binary blends represents a cost-effective strategy to obtain a good combination of physical properties and also to reduce the final cost of the biopolymers. This consists of mixing two dissimilar biopolymers in order to obtain formulations with intermediate or better performance than those of the neat biopolymers. In this sense, on the one hand, bio-based polyethylene (bio-PE) combines natural origin with the easy processability and optimal performance of polyolefins. In this sense, highdensity polyethylene (HDPE) is among the top five plastic materials in the world in terms of volume, reaching 31.3 million tons in $2009 . .^{7}$ On the other hand, polylactide (PLA) is currently the most used bio-based and biodegradable polyester. PLA is obtained through the polycondensation reaction of lactides, the dimers that are, in turn, obtained from the fermentation of sugars based on starch. ${ }^{8}$ Currently, PLA is considered the front runner in the emerging market of bioplastics due to its good balance between mechanical, thermal, and barrier properties, and its double environmental advantage of being a bio-based and biodegradable material. For these reasons, it is now widely used in $3 \mathrm{D}$ printing, ${ }^{9}$ biomedical applications, ${ }^{10,11}$ automotive and textiles, ${ }^{12}$ packaging, 13 etc.

Recycling is an interesting solution to minimize plastic wastes but its main drawbacks are related to collection and separation, particularly in the case of multilayers. Polyolefins such as polyethylene (PE) and polypropylene (PP) are, with difference, the most recycled polymers but sometimes, due to the difficulty in separating polymers, they can be recycled with low amounts of other polymers (even immiscible) without compromising their overall performance. As mentioned above, PLA is gaining interest at industrial scale and, therefore, it is everyday more present in plastic wastes that can be potentially subjected to recycling. As it is a relatively new polymer in plastic waste streams (with a relatively low percentage in comparison to other polymers), separation is still complex and expensive at this stage, so that, PLA could be present in low amounts in recycled PE and PP streams, leading to complex blends. Polyolefins are highly hydrophobic polymers (non-polar) while, in general, thermoplastic polyesters are more hydrophilic (polar) due to the presence of ester groups and other oxygenbased groups. This difference in polarity leads to a high difference between their solubility parameters $(\delta)$. In fact, the $\delta$ value of PE is close to $16.0 \mathrm{MPa}^{1 / 2}$ while PLA shows a typical value of $20 \mathrm{MPa}^{1 / 2}$, resulting in a poor or lack of miscibility between them. ${ }^{4,14-17}$

The mixture of polymers with a dissimilar physical properties is widely considered as an economic technique to produce plastic materials that have a desirable combination of properties and may also have the ability to recycle or degrade after usage.18,19 However, one of the main problems of the blends made of polyolefins and polyesters is 
that they present total immiscibility. When mixed together, the resultant polymer blends turn out to have a two-phase morphology in which the main component forms a matrix and the minor component appears as the dispersion phase in the form of spheres, platelets or even fibrils. ${ }^{20}$ Unfortunately, immiscible mixtures are frequently characterized by a poor adhesion between the phases and they generally require compatibility for achieving improved performance..$^{21}$

Two main methods can be applied to improve the miscibility between two or more immiscible polymers, namely ex situ (non-reactive) or in situ (reactive) compatibilization. ${ }^{22} \mathrm{Ex}$ situ compatibilization is based on the use of a premade (block or grafted) copolymer, being highly miscible with the blend components that are obtained under careful design and synthesis. Usually, these copolymers possess dual functionality, which means that a chain segment (with a particular chemical structure) can interact with one polymer in the blend and the other segment chain (with other chemical groups) can establish some interactions with the other polymer in the blend, thus acting as a bridge between them. These tailor-made copolymers can reduce particle size, increase morphological stability and interfacial adhesion, and improve final mechanical properties. ${ }^{23}$ Some copolymers have been specifically designed for PLA $^{24,25}$ or PE, 22,26 providing good results as compatibilizers. ${ }^{27}$ The second method to improve the compatibility in polymer blends is the use of in situ (reactive) compatibilization, the so-called reactive extrusion (REX), during the compounding of the polymer formulation. ${ }^{28,29}$ In situ compatibilization is carried out by means of polymers, oligomers, and additives containing multi-functional groups (e.g. anhydride, epoxy, oxazoline, isocyanates, etc.) that are capable of reacting during the extrusion process with the functional groups (e.g. hydroxyl and carboxyl terminal groups of condensation polymers) to form new copolymers. 29,30 REX is a straightforward and cost-effective technique for polymer processing in which dicumyl peroxide (DCP), a free radical initiator widely used in polymerization processes, can be additionally used as an initiator and cross-linker. ${ }^{31}$ Indeed, DCP has been used to promote the compatibilization of immiscible polymers in different polymer binary blends with good results. For instance, Garcia-Garcia et al.32 improved the compatibility between poly(3-hydrobutyrate) (PHB) and poly(e-caprolactone) (PCL) by the addition of DCP. Moreover, in a more sustainable context, derivatives of natural oils, such as acrylated, 4 epoxidized ${ }^{32}$ or maleinized vegetable oils, ${ }^{4,33}$ can be used as reactive additives to improve the properties of biopolymers and also to achieve compatibility in polymer blends or even in green composites. Among them, epoxidized linseed oil and, more lately, maleinized linseed oil (MLO) currently represent a sustainable solution in PLAbased formulations. $4,34-36$

Bio-based high-density polyethylene (bio-HDPE), also called "microbial" or "green" HDPE, is a polyolefin produced by conventional polymerization of ethylene obtained by catalytic dehydration of bioethanol. ${ }^{37}$ Bio-HDPE has the same physical properties than its counterpart petrochemical resin, particularly having a good mechanical resistance, high ductility, and improved water resistance. ${ }^{38}$ Injection-molded pieces of bio-HDPE can be targeted to manufacture rigid plastic parts for packaging materials and surfaces (e.g. cutting boards, kitchen utensils and countertops, and storage containers). ${ }^{39}$

The aim of this study was to prepare binary blends of bio-HDPE with PLA by melt compounding in order to develop a cost-effective and fully renewable material with high mechanical strength and rigidity but with still sufficient mechanical ductility. To 
this end, this work explores the use of different reactive additives as compatibilizers, such as copolymers and grafted polymers, multi-functionalized vegetable oils, and a cross-linking agent, to enhance the miscibility between both biopolymers and obtain the more balanced mechanical performance.

\section{EXPERIMENTAL}

\subsection{Materials}

Bio-HDPE was SHA7260, a grade for injection molding supplied by FKuR Kunststoff $\mathrm{GmbH}$ (Willich, Germany) and manufactured by Braskem (São Paulo, Brazil). It has a density of $0.955 \mathrm{~g} / \mathrm{cm}^{3}$ and a melt flow index (MFI) of $20 \mathrm{~g} / 10$ min measured at $190{ }^{\circ} \mathrm{C}$ and $2.16 \mathrm{~kg}$. Its minimum bio-based content is $94 \%$, as determined by the manufacturer according to ASTM D6866. Commercial PLA Ingeo ${ }^{\mathrm{TM}}$ biopolymer 6201D was obtained from NatureWorks (Minnetonka, MN, USA). This PLA grade has a density of 1.24 $\mathrm{g} / \mathrm{cm}^{3}$ and a melt flow rate (MFR) of $15-30 \mathrm{~g} / 10 \mathrm{~min}$, measured at $210^{\circ} \mathrm{C}$ and $2.16 \mathrm{~kg}$, which makes it suitable for injection molding.

Polyethylene-grafted maleic anhydride (PE-g-MA) and poly(ethylene-co-glycidyl methacrylate) (PE-co-GMA), with reference numbers 456624 and 430862, respectively, and MFI values of $5 \mathrm{~g} / 10 \mathrm{~min}\left(190{ }^{\circ} \mathrm{C} / 2.16 \mathrm{~kg}\right)$, were obtained from Sigma-Aldrich S.A. (Madrid, Spain). These two PE-based copolymers were selected due to their dual functionality: non-polar polyethylene segments and polar segments, either with maleic anhydride (MA) or glycidyl methacrylate (GMA) groups, that can readily react with the hydroxyl groups of the PLA end-chains. MLO, a maleinized vegetable oil from linseed oil, was obtained from Vandeputte (Mouscron, Belgium) as VEOMER LIN. This multi-functional reactive oil was selected due to its dual functionality since it contains non-polar fatty acids and polar maleic anhydride-grafted fatty acids. The oil has a viscosity of $1000 \mathrm{cP}$ at $20^{\circ} \mathrm{C}$ and an acid value of 105-130 mg potassium hydroxide $(\mathrm{KOH}) / g$. Finally, DCP, with $98 \%$ purity, was purchased from Sigma-Aldrich S.A. (Madrid, Spain) and used to provide free radicals during the REX process. Figure 1 shows the chemical structure of each compatibilizer.

\subsection{Preparation of biopolymer blends}

REX was carried out in a co-rotating twin-screw extruder from Construcciones Mecánicas Dupra, S.L. (Alicante, Spain). The speed of the screws, having a diameter of $25 \mathrm{~mm}$ with a ratio of length (L) to diameter (D), that is, L / D of 24, was set at $25 \mathrm{rpm}$ and the extrusion temperature profile, from the hopper to the die, was set as follows: 165-170-175-180 ${ }^{\circ} \mathrm{C}$. All materials were fed through the main hopper, being previously pre-homogenized in a zipper bag. These were extruded through a round die to produce strands and pelletized using an air-knife unit. In all cases, residence time was approximately $1 \mathrm{~min}$. Table 1 gathers the set of materials prepared during extrusion. The additives were added as parts per hundred resin (phr) of biopolymer.

The compounded pellets were, thereafter, shaped into pieces by injection molding in a Meteor 270/75 from Mateu \& Solé (Barcelona, Spain). The temperature profile was 165 
${ }^{\circ} \mathrm{C}$ (hopper), $170{ }^{\circ} \mathrm{C}, 175{ }^{\circ} \mathrm{C}$, and $180{ }^{\circ} \mathrm{C}$ (injection nozzle). A clamping force of 75 tons was applied while the cavity filling and cooling time were set at 1 and $10 \mathrm{~s}$, respectively. Pieces with a thickness of $4 \mathrm{~mm}$ were produced. Figure 2 shows a schematic representation of the manufacturing process.

\subsection{Mechanical characterization}

The tensile tests were performed in a universal testing machine ELIB 50 of S.A.E. Ibertest (Madrid, Spain) as recommended by ISO 527-1:2012. The tests were carried out with a load cell of $5 \mathrm{kN}$ and the loading speed was set to $40 \mathrm{~mm} / \mathrm{min}$.

The hardness measurements were done according to ISO 868:2003, using a Model 676D durometer (J. Bot Instruments S.A., Barcelona, Spain). The impact resistance was measured using a 1-J Charpy pendulum test machine from Metrotec S.A. (San Sebastián, Spain) in rectangular pieces with dimensions of $4 \times 10 \times 80 \mathrm{~mm}^{3}$ and a $0.25-\mathrm{mm}$ radius v-notch, according to the specifications of ISO 179-1:2010.

All samples were analyzed at room temperature, that is, $25^{\circ} \mathrm{C}$, and at least 6 samples of each material were tested and their values averaged.

\subsection{Morphological characterization}

The morphology of the fracture surfaces of the biopolymer pieces obtained from the impact tests was observed by field emission scanning electron microscopy (FESEM) in a ZEISS ULTRA 55 from Oxford Instruments (Abingdon, UK). Prior to placing the samples in the vacuum chamber, the surfaces were sputtered with a gold-palladium alloy in an EMITECH sputter coating SC7620 model from Quorum Technologies, Ltd. (East Sussex, UK). An acceleration voltage of $2 \mathrm{kV}$ was applied.

\subsection{Thermal characterization}

The main thermal transitions of the biopolymer pieces were obtained by differential scanning calorimetry (DSC) in a Mettler-Toledo 821 calorimeter (Schwerzenbach, Switzerland). An average sample weight of 5 to $7 \mathrm{mg}$ was subjected to a thermal cycle as follows: initial heating from $25^{\circ} \mathrm{C}$ to $200{ }^{\circ} \mathrm{C}$, cooling to $-50^{\circ} \mathrm{C}$, and second heating to $300{ }^{\circ} \mathrm{C}$, at a heating rate of $10^{\circ} \mathrm{C} / \mathrm{min}$. All tests were performed under a nitrogen atmosphere $(66 \mathrm{~mL} / \mathrm{min})$ with standard sealed aluminum crucibles with a volume capacity of $40 \mu \mathrm{L}$.

Thermogravimetric analysis (TGA) was carried out in a Mettler-Toledo TGA/SDTA 851 thermobalance (Schwerzenbach, Switzerland). Samples, with an average weight between 5 and $7 \mathrm{mg}$, were placed in standard alumina crucibles $(70 \mu \mathrm{L})$ and subjected to a heating program from $30{ }^{\circ} \mathrm{C}$ to $700{ }^{\circ} \mathrm{C}$ at a heating rate of $20{ }^{\circ} \mathrm{C} / \mathrm{min}$ in air atmosphere.

All thermal tests were performed in triplicate. 


\subsection{Thermomechanical characterization}

221 Dynamical mechanical thermal analysis (DMTA) was carried out in a DMA1 dynamic 222 analyzer from Mettler-Toledo (Schwerzenbach, Switzerland), working in single cantilever flexural conditions. Samples with dimensions of $20 \times 6 \times 2.7 \mathrm{~mm}^{3}$ were subjected to a temperature sweep from $-160{ }^{\circ} \mathrm{C}$ to $100{ }^{\circ} \mathrm{C}$ at a constant heating rate of 2 ${ }^{\circ} \mathrm{C} / \mathrm{min}$. The selected frequency was $1 \mathrm{~Hz}$ while the maximum flexural deformation was $10 \mu \mathrm{m}$.

The dimensional stability of the injection-molded pieces was estimated by thermomechanical analysis (TMA) in a Q-400 thermoanalyzer from TA Instruments

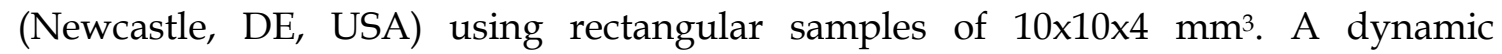
temperature ramp was programmed from $-160{ }^{\circ} \mathrm{C}$ to $100{ }^{\circ} \mathrm{C}$, at a heating rate of 3 ${ }^{\circ} \mathrm{C} / \mathrm{min}$ and a constant load of $0.02 \mathrm{~N}$.

All thermomechanical tests were run in triplicate.

\section{RESULTS ANS DISCUSION}

\subsection{Mechanical properties}

The mechanical characterization of the injection-molded pieces made of bio-HDPE and its blends with PLA provides relevant information in terms of the effect of the blend composition and the tested additives as well as their most suitable applications. Table 2 shows the values of tensile modulus $\left(E_{\text {tensile }}\right)$, maximum tensile strength $\left(\sigma_{\max }\right)$, elongation at break $\left(\varepsilon_{\mathrm{b}}\right)$ of the pieces obtained from the tensile tests. One can observe that the neat bio-HDPE piece presented values of $E_{\text {tensile }}$ and $\sigma_{\max }$ of $408.4 \mathrm{MPa}$ and 21.6 $\mathrm{MPa}$, respectively, while $\varepsilon_{\mathrm{b}}$ was $545.2 \%$, indicating that the material was relatively rigid and with a high ductility. The incorporation of PLA into bio-HDPE resulted in rigidity increase of the pieces, that is, the $\mathrm{E}_{\text {tensile }}$ values varied from $492.9 \mathrm{MPa}$, for the piece containing $5 \mathrm{wt} \%$ PLA, up to $563 \mathrm{MPa}$, for the piece with $20 \mathrm{wt} \%$ PLA. However, while the $\sigma_{\max }$ was kept in the same range or even showed slightly higher values than the neat bio-HDPE piece, that is, in the 21.5-23.5 MPa range, the $\varepsilon_{b}$ values of the pieces significantly decreased with the PLA content. For instance, the bio-HDPE/20PLA piece showed a $\varepsilon_{b}$ value of $54 \%$, that is, approximately 10 times lower than that observed for the neat bio-HDPE. The reduction induced in the ductile properties suggests a poor stress transfer between the two biopolymer phases in which, more likely, the PLA phase acted as a stress concentrator in the bio-HDPE matrix favoring the rupture of the pieces.

The addition of the different compatibilizers was analyzed on the bio-HDPE/20PLA pieces. It can be observed that the studied compatibilizers induced very dissimilar effects on the mechanical properties of the binary blend pieces. In relation to the PEbased compatibilizers, both PE-g-MA and PE-co-GMA delivered a similar

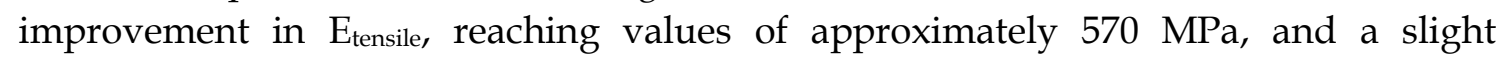
reduction in $\sigma_{\max }$. In contrast, the addition of PE-g-MA slightly increased $\varepsilon_{\mathrm{b}}$, reaching a 
value of $57.7 \%$, while PE-co-GMA induced a significant reduction in ductility down to a value of $34.4 \%$. This suggests that the latter additive could produce certain crosslinking in the biopolymer blend. Similar results were obtained, for instance, by Abdolrasouli et al. ${ }^{40}$ using PE-g-MA as compatibilizer in PLA/PE blends containing organoclays. In particular, it was observed that the PLA/PE/PE-g-MA 80/12/8 (wt/wt) blends increased $\varepsilon_{\mathrm{b}}$ around 30\%, while the tensile strength properties remained almost constant in comparison to an unmodified PLA/PE blend. In this sense, it is worthy to note that the selected PE-based compatibilizers show dual functionality. On one hand, the hydrophobic PE blocks and, on the other hand, the highly polar and reactive MA and GMA groups. The PE blocks/segments can then interact with the bio-HDPE chains in the blend while both the MA and GMA groups can readily react/interact with the hydroxyl groups of PLA through esterification and etherification reactions, respectively. This way, the PE-based compatibilizer chains tended to place at the interface between the bio-HDPE and PLA phases thus acting as a bridge between the two immiscible phases. This partial compatibilization has been reported to yield improved miscibility and allows somewhat load transfer between both polymers in the blend, thus, overcoming (or minimizing) the negative effects of immiscibility. ${ }^{41,42}$

In the case of MLO, the addition of the vegetable oil generated pieces with similar or slightly lower mechanical properties than the neat bio-HDPE/20PLA piece. This reduction in the mechanical strength has been previously related to the plasticizing effect of MLO on the PLA matrix, in which the multi-functionalized oil also produced an increase in ductility. 4,35 However, the absence of improvement in the $\varepsilon_{b}$ value of the here-described pieces suggests that the vegetable oil presented a low solubility and, thus, a poor effect on the bio-HDPE matrix. Interestingly, the combination of MLO and DCP resulted in more rigid injection-molded pieces, showing the highest $E_{\text {tensile value }}$ among the tested pieces, that is, $582 \mathrm{MPa}$, and the lowest $\varepsilon_{\mathrm{b}}$ value, that is, $23.2 \%$. As similar to the PE-co-GMA-treated piece, it can be considered that the addition of the peroxide additive generated a cross-linked structure in the polymer blend. The crosslinking effect of DCP has been tested in different polymers, blends, and composites. ${ }^{43-46}$ Similar results were observed, for instance, by Sen-lin Yang et al. ${ }^{47}$ where the DCP addition resulted in a cross-linking of the PLA structure, yielding a stiffened material with a higher $E_{\text {tensile }}$ and lower $\varepsilon_{\mathrm{b}}$.

Table 2 also shows the values of Shore D hardness and impact strength of the biopolymer pieces. Similar to the tensile tests, the addition of PLA induced an increase in hardness and a reduction in toughness in comparison to the neat bio-HDPE piece. In particular, while the neat bio-HDPE piece presented a Shore D hardness of 61.8 and an impact-strength value of $3.77 \mathrm{~kJ} / \mathrm{m}^{2}$, the addition of PLA progressively increased hardness up to 67.4 , while it decreased impact strength up to $1.70 \mathrm{~kJ} / \mathrm{m}^{2}$, both values for the bio-HDPE/20PLA piece. Similar to the tensile properties, the use of PE-g-MA slightly increased hardness but reduced impact strength. As opposite, PE-co-GMA produced pieces with similar hardness but a higher toughness. In particular, the impact-strength value increased to $2.01 \mathrm{~kJ} / \mathrm{m}^{2}$, that is, an increase of approximately $18 \%$. For the MLO-containing piece, hardness was lower, that is, 58.8 , while the impact strength was significantly increased, reaching a value of $3.96 \mathrm{~kJ} / \mathrm{m}^{2}$, representing an improvement close to $133 \%$. This observation points to the fact that the multi- 
functionalized oil was probably preferentially incorporated in the PLA-rich regions as a dispersed phase. A similar effect was previously observed for PLA pieces containing acrylated epoxidized soybean oil, ${ }^{4}$ in which the multi-functionalized oil was dispersed in the form of fine droplets contributing to increasing the impact-absorbed energy in a similar way as, for instance, polybutadiene rubbers do in high-impact polystyrene. This remarkable toughening effect was maintained for the injection-molded piece produced with MLO in combination to DCP, which also showed hardness values close to those of the neat bio-HDPE/20PLA.

Although the dual incorporation of DCP and MLO improved the impact strength of the bio-HDPE/20PLA piece it also resulted in a slight reduction of $0.25 \mathrm{~kJ} / \mathrm{m}^{2}$ with respect to the MLO-containing bio-HDPE/20PLA piece. This effect can be thus ascribed to the cross-linking effect of DPC on the binary blend, which resulted in a more interconnected network of biopolymer chains that increased the mechanical resistance of the pieces but also reduced its toughness. In this sense, it has been reported that DCP can be effectively applied as a reactive compatibilizer in polymers blends since it decomposes and acts as a free radical initiator. ${ }^{42}$ For instance, GarciaGarcia et al. ${ }^{48}$ prepared PHB and PCL blends compatibilized with DCP. It was observed that DCP not only promoted the formation of macroradicals of each biopolymer that, thereafter, led to the formation of in situ PHB-co-PCL copolymers that contributed to improving compatibilization and forming partially cross-linked networks in the blends, but also the PCL-rich domains could establish stronger interactions with the PHB polymer matrix. Hence, the use of DCP during the melt mixing of polymer blends can yield a series of grafted, branched, and/or cross-linked structures in polymer blends. ${ }^{49}$

\subsection{Morphological characterization}

Figure 3 includes the FESEM images of the fracture surfaces of the biopolymer pieces after the impact tests. Figure $\mathbf{3 a}$, corresponding to the neat bio-HDPE piece, shows a fracture surface with a very irregular and rough appearance presenting the typical cavernous formations of a polymer with a ductile behavior. Due to the low miscibility between both biopolymers, one can observe in Figures $\mathbf{3 b}$ to $\mathbf{3 e}$ that PLA remained incorporated into the bio-HDPE matrix as a dispersed phase in the form of micro-sized spherical domains or droplets generating an "island-and-sea" morphology. The absence of a co-continues phase morphology in the blends supports previous studies indicating that, at the here-studied mixing ratios, these biopolymers are thermodynamically immiscible. ${ }^{50}$ Additionally, these droplets were larger as the percentage of the added PLA was increased. In particular, the size of these droplets ranged between 1-2 $\mu \mathrm{m}$ for the bio-HDPE/5PLA piece, 2-3 $\mu \mathrm{m}$ for the bioHDPE/10PLA piece, 3-5 $\mu \mathrm{m}$ for the bio-HDPE/15PLA piece, and 4-8 $\mu \mathrm{m}$ for the bioHDPE/20PLA piece. One can also observe the existence of a gap or a lack of continuity between the PLA droplets and the bio-HDPE matrix, which was more noticeable in the pieces with the highest PLA contents, shown in Figures $\mathbf{3 d}$ and $\mathbf{3 e}$. In addition, the fracture surfaces presented several holes, suggesting a phenomenon of phase debonding after breakage. Both the presence of gaps and holes further indicates the lack of compatibility between the two phases, therefore suggesting that the presence of 
the PLA microdroplets acted as stress concentrators rather than a reinforcing element. This would explain the above-described mechanical performance of the bioHDPE/PLA pieces, by which when the pieces are subjected to external stresses the microdroplets are responsible for their loss of intrinsic ductility.

In relation to the effect of the different tested compatibilizers, one can observe that the surface fracture of the piece treated with PE-g-MA, shown in Figure 3f, presented a similar morphology than that of the neat bio-HDPE/20PLA piece. However, the mean size of the PLA droplets was slightly lower, that is, 4-6 $\mu \mathrm{m}$, and the number of voids was also reduced. This reduction of the PLA domains was more evident in the case of the pieces treated with PE-co-GMA, where the mean droplets size was in the 1-2 $\mu \mathrm{m}$ range. Moreover, the gap at the interface between the two polymers was significantly reduced. This suggests that a higher coalescence stabilization in the biopolymer blend was successfully achieved due to a reduced surface tension between the phases. This phenomenon would then explain the improved capacity of energy absorption observed during the impact tests. A similar morphological effect was previously observed by Wang et al.51 when PE-g-MA was used as a compatibilizer between HDPE and poly(ethylene-co-vinyl alcohol) (EVOH). It was observed that the domain size of EVOH decreased in the HDPE matrix when 10 phr PE-g-MA were used while the phase boundaries disappeared as its content was higher than 20 phr. Similarly, QuirozCastillo et al. 52 showed positive results in low-density polyethylene (LDPE)/chitosan blends due to the incorporation of $5 \mathrm{wt} \%$ PE-g-MAH.

In Figure $3 g$ one can observe the surface fracture of the blend piece processed with MLO. Noticeably, the droplets became larger, leading to the formation of big droplets that also presented some stretching phenomenon along the bio-HDPE matrix. Further observation at the droplet cross-sections revealed the presence of ultrathin enclosed droplets or pores, which supports the above-described hypothesis that MLO was mainly incorporated into the PLA phase. In any case, a large gap between the bioHDPE and PLA phases could be still discerned and, hence, the multi-functionalized vegetable oil failed to yield compatibilization to the blend. Interestingly, the surface fracture of the bio-HDPE/20PLA piece processed with MLO and DCP revealed the presence of a continuous structure. Indeed, the dispersed PLA droplets were mostly no longer discerned and it gave rise to the formation of a morphology in which the bioHDPE matrix fully covered the enclosed PLA regions. In particular, these PLA regions showed a dendritic or branch-like shape, being produced during fracture as a result of the high interaction between the two biopolymers. The fracture also produced a rougher surface with certain plastic deformation where no evidence of phase separation or pull-out of the inclusion phase after fracture was observed. This morphological change can be attributed to both the in situ formation of bio-HDPE-coPLA copolymers to achieve compatibilization and the cross-linking effect of DCP, above described during the mechanical analysis, which produced a fully interconnected bio-HDPE/PLA structure. The previous work carried out by Ma et al. ${ }^{53}$ showed that DCP is able to compatibilize PLA/ PBAT blends by the formation of an insitu formed PLA-g-PBAT copolymer, reducing the size of the PBAT domains embedded in the PLA matrix from $1.0 \mu \mathrm{m}$ to $0.6 \mu \mathrm{m}$ after addition of $0.1 \mathrm{wt} \%$ DCP. In another work, Li et al. ${ }^{54}$ observed that the addition of $0.5 \%$ DCP to polyamide $11 / \mathrm{EVOH}$ blends favored the formation of more fine spherical domains. Moreover, 
large number of thinner and longer embedded flat-like structures of EVOH were obtained when $1.5 \%$ DCP was added.

\subsection{Thermal characterization}

Figure 4 shows the DSC curves during the second heating of the biopolymer pieces. One can observe that the neat bio-HDPE presented a melting temperature $\left(\mathrm{T}_{\mathrm{m}}\right)$ of 132.2 $\pm 1.5{ }^{\circ} \mathrm{C}$. The addition of PLA generated a second endothermic peak, related to the melting of PLA, which was observed in the $160-180{ }^{\circ} \mathrm{C}$ range. For the bioHDPE/20PLA blend instance, this peak was centered at approximately at $169.6 \pm 0.7$ ${ }^{\circ} \mathrm{C}$. The second peak intensity was relatively low though it was more noticeable at high PLA contents, that is, 15 and $20 \mathrm{wt} \%$. Additionally, it can be observed that the $\mathrm{T}_{\mathrm{m}}$ values of the bio-HDPE phase slightly decreased gradually with increasing the PLA content, up to $131.4 \pm 1.1{ }^{\circ} \mathrm{C}$, for the bio-HDPE/20PLA blend. The melting enthalpies were also lower in the blend formulations with higher PLA contents. In overall, the thermal values remained almost constant, which confirmed the poor compatibility or absence of miscibility between both biopolymers. A similar observation was previously obtained in, for instance, PLA/PP blends. .55

With the incorporation of the different compatibilizers, some interesting changes in the thermal properties of the injection-molded pieces could be observed. While the melting profile of the blends remained nearly constant with the addition of both PE-g-MA and PE-co-GMA, the use of MLO in combination with DCP produced both an increase in the $\mathrm{T}_{\mathrm{m}}$ value related to the bio-HDPE phase, that is, $134.5 \pm 1.0^{\circ} \mathrm{C}$, and a decrease for the PLA phase, that is, $167.2 \pm 0.8{ }^{\circ} \mathrm{C}$. This slight shift in the characteristic melting profiles of HDPE and PLA can be related to the formation of some HDPE- $g$-PLA copolymer chains due to the action of DCP, which can provide free radicals to attach the HDPE chains, and MLO, which can react with the hydroxyl groups in PLA and also provide plasticization. Although the change was not substantial, it gives some evidence of the synergistic compatibilizing effect of DCP and MLO on the blends of bio-HDPE with PLA. Similar findings were reported by, for instance, Lai et al.56 in binary blends of PLA with thermoplastic polyurethane (TPU) compatibilized with aminosilane. A depression in the characteristic melting peak of PLA was attributed to a lubrication provided by the compatibilized chains with a low molecular weight $\left(\mathrm{M}_{\mathrm{W}}\right)$. Although MLO, as similar to other vegetable oils, is able to plasticize PLA and then to increase its free volume and reduce the biopolymer-biopolymer interactions, ${ }^{4}$ this effect was not observed in the neat MLO-containing blend piece, suggesting that the addition of DCP favored certain miscibility for the whole blend system. In any case, the absence of significant melting peak shifts towards intermediate temperatures, in between the melting peaks of each polymer in the blend, confirmed the presence of two phases with different crystal types and therefore the absence of a fully miscible structure. ${ }^{22}$

In relation to thermal stability, Figure 5 shows the TGA curves for the here-prepared biopolymer pieces whereas Table 3 summarizes the obtained values from the curves. The neat bio-HDPE piece presented an onset degradation temperature, defined as the temperature at which the material losses $5 \%$ of its mass $\left(\mathrm{T}_{5} \%\right)$, of $312.5 \pm 1.7{ }^{\circ} \mathrm{C}$. Its 
degradation temperature $\left(\mathrm{T}_{\mathrm{deg}}\right)$, determined at the temperature when the mass loss was maximum, was $455.2 \pm 1.5^{\circ} \mathrm{C}$. Additionally, the green polyolefin degraded in a single stage, giving a residual mass of $0.3 \pm 0.2 \%$. A similar thermal degradation profile has been recently observed by Montanes et al. ${ }^{.7}$ for bio-HDPE. Interestingly, it can be seen that the incorporation of PLA positively delayed the degradation onset of bio-HDPE, up to values in the range of $324-329{ }^{\circ} \mathrm{C}$, but it also reduced the values of $\mathrm{T}_{\text {deg. }}$. In particular, the TGA curves presented two main weight losses. The first one occurred from $320^{\circ} \mathrm{C}$ to $390{ }^{\circ} \mathrm{C}$, which can be related to the initial thermal decomposition of bioHDPE and mainly to the whole thermal degradation of the PLA phase. The second one was observed in the $400-510{ }^{\circ} \mathrm{C}$ range, which can be ascribed to the chain-scission process of bio-HDPE. In this sense, Garcia-Campo et al. ${ }^{58}$ has recently analyzed the thermal degradation of PLA, showing that the thermal decomposition of the biopolyester occurs in one single step, in the $300-400{ }^{\circ} \mathrm{C}$ range, with $\mathrm{T}_{5 \%}$ and $\mathrm{T}_{\mathrm{deg}}$ values of $328.5^{\circ} \mathrm{C}$ and $368.5^{\circ} \mathrm{C}$, respectively.

While the incorporation of both PE-g-MA and PE-co-GMA compatibilizers induced no changes in the thermal stability of the bio-HDPE/20PLA pieces, the MLO-containing pieces presented a slight improvement. In particular, the values of $\mathrm{T}_{5 \%}$ increased from $324.9 \pm 1.6{ }^{\circ} \mathrm{C}$, for the neat the bio-HDPE/20PLA piece, to $332.9 \pm 2.1^{\circ} \mathrm{C}$ and $338.9 \pm 1.4$ ${ }^{\circ} \mathrm{C}$, for the pieces containing MLO and MLO with DPC, respectively. In the case of $\mathrm{T}_{\mathrm{deg}}$, the first degradation peak was also delayed from $358.1 \pm 2.0^{\circ} \mathrm{C}$, for the neat the bioHDPE/20PLA piece, to $360.9 \pm 2.1^{\circ} \mathrm{C}$ and $365.1 \pm 1.9^{\circ} \mathrm{C}$, for the pieces containing MLO and MLO with DPC, respectively. An increase in thermal stability by the incorporation of multi-functionalized vegetable oils has already been reported in some of our previous works, 4,34 which was related to the development of a macromolecule with a higher $\mathrm{M}_{\mathrm{W}}$. In the case of the piece treated with MLO and DCP, the thermal stability improvement can be ascribed to the partial cross-linking achieved in the blend. In this sense, it has been reported that the thermal stability of biopolymers can be improved, to a certain extent, with the addition DCP. ${ }^{32,59}$ In relation to the residual mass, it can be seen that, in all cases, small residual amounts in the $0.1-0.5 \%$ range were produced.

\subsection{Thermomechanical characterization}

Figure 6a presents the evolution of the storage module ( $\left.\mathrm{G}^{\prime}\right)$ in the here-developed bioHDPE/PLA pieces from $-150{ }^{\circ} \mathrm{C}$ to $100{ }^{\circ} \mathrm{C}$. In relation to the neat bio-HDPE piece, a sharp decrease of $\mathrm{G}^{\prime}$ was produced up to $-100^{\circ} \mathrm{C}$, which can be related to the glass-torubber transition of the green polyolefin. Then, it progressively decreased as the test temperature increased due to a softening effect of the bio-HDPE matrix. The incorporation of PLA into the bio-HDPE matrix induced a slight decrease in $\mathrm{G}^{\prime}$, which was more pronounced as the percentage of PLA increased. In particular, at $-150{ }^{\circ} \mathrm{C}$, it decreased from $2493 \mathrm{MPa}$, for the neat bio-HDPE piece, to $2140 \mathrm{MPa}$, for the bioHDPE/20PLA piece. This reduction was observed up to temperatures close to $0{ }^{\circ} \mathrm{C}$, which supposed a decrease in the overall rigidity of the material. Similar to other physical properties, the addition of both PE-g-MA and PE-co-GMA resulted in a similar thermomechanical profile whereas the MLO induced some relevant changes. In the case of the neat MLO-treated bio-HDPE/PLA piece, lower $G^{\prime}$ values were observed in the whole temperature range. This reduction has been ascribed to the intrinsic 
plasticizing effect provided by MLO on polyesters. ${ }^{4}$ In any case, the $G$ ' reduction was relatively low, indicating that the oil mainly plasticized the dispersed PLA phase, as described above during the morphological analysis. The combined use of MLO and DCP provided, in a similar way to the mechanical and thermal properties described above, the highest rigidity increase. This change was mainly seen in the temperature range from $-100{ }^{\circ} \mathrm{C}$ to $-25^{\circ} \mathrm{C}$, while at higher temperatures all pieces presented a similar thermomechanical performance. For instance, at $-25{ }^{\circ} \mathrm{C}$, the $\mathrm{G}^{\prime}$ value increased from 1229.5 MPa, for the neat bio-HDPE/20PLA piece, to $1369.6 \mathrm{MPa}$, for the same piece processed with MLO and DCP.

Figure $\mathbf{6 b}$ shows the evolution of the damping factor $(\tan \partial)$ in the bio-HDPE/PLA pieces. The peak located between $-112{ }^{\circ} \mathrm{C}$ and $-116{ }^{\circ} \mathrm{C}$ in the bio-HDPE piece sample corresponds to alpha ( $\alpha$ )-relaxation of the green polyolefin, which is related to its glass transition temperature $\left(\mathrm{T}_{\mathrm{g}}\right)$. The PLA blending generated a second peak, seen in the $65-75^{\circ} \mathrm{C}$ range, which can be similarly related to the a-relaxation of PLA. The addition of the compatibilizers induced almost no change in the a-relaxation peak of bio-HDPE, while they slightly reduced that of PLA. In the case of PE-g-MA and PE-co-GMA, this reduction was of only $3-4{ }^{\circ} \mathrm{C}$ while the MLO and MLO combined with DCP reduced approximately by 7 and $11{ }^{\circ} \mathrm{C}$, respectively, the a-relaxation peak of PLA. This thermomechanical change can be ascribed to the above-mentioned process of plasticization of the PLA phase by MLO while, particularly for the piece also treated with $\mathrm{DCP}$, this further confirms the improved compatibilization by the peroxide. Indeed, the study of $\mathrm{T}_{\mathrm{g}}$ gives an indication of the level of miscibility in polymer blends. Briefly, thermodynamically immiscible blends show different distinguishable $\mathrm{T}_{\mathrm{g}}$ values, partially miscible blends have tendency to shift the $T_{g}$ value of one component toward that of the other, and blends made of two polymers that constitute a completely miscible blend present a single $\mathrm{T}_{\mathrm{g} .}{ }^{22}$ Therefore, the here-observed shift of $\mathrm{T}_{\mathrm{g}}$ for the PLA phase with the combined used of MLO and DCP further supports the partial miscibility with bio-HDPE in the binary blends. Similar results were obtained by Wang et al.60 for thermoplastic dry starch (DTPS) blends with PLA compatibilized by MA in the presence of DCP. In particular, $\mathrm{T}_{\mathrm{g}}$ of DTPS shifted to a higher temperature, while PLA's $\mathrm{T}_{\mathrm{g}}$ moved to a lower temperature.

In addition to DMTA, the dimensional stability was evaluated by TMA. To this end, the coefficient of linear thermal expansion (CLTE) was studied in the injection-molded pieces and the obtained results are summarized in Table 4 . Below $\mathrm{T}_{\mathrm{g}}$ of bio-HDPE, that is, $-110^{\circ} \mathrm{C}$, one can observe that the PLA addition to the mixture slightly reduced the CLTE values, making the pieces somewhat stiffer in their glassy region. In particular, it was decreased from $112.7 \pm 0.3 \mu \mathrm{m} / \mathrm{m}^{\circ} \mathrm{C}$, for the neat bio-HDPE piece, to $107.6 \pm 1.2$ $\mu \mathrm{m} / \mathrm{m}^{\circ} \mathrm{C}$, for the bio-HDPE/20PLA piece. The incorporation of the different compatibilizers further enhanced the reduction of the CLTE values, reaching the lowest CLTE value for the piece processed with MLO and DCP, that is, $90.6 \pm 1.3 \mu \mathrm{m} / \mathrm{m}^{\circ} \mathrm{C}$. As the temperature was increased during the test, the CLTE values also increased. In the temperature range between both $\mathrm{T}_{\mathrm{g}} \mathrm{s}$, that is, from $-110{ }^{\circ} \mathrm{C}$ to $70{ }^{\circ} \mathrm{C}$, the same trend was observed. The addition of PLA reduced the CLTE values from $134.0 \pm 0.4 \mu \mathrm{m} / \mathrm{m}^{\circ} \mathrm{C}$, for the neat bio-HDPE piece, to $94.3 \pm 1.1 \mu \mathrm{m} / \mathrm{m}^{\circ} \mathrm{C}$, for the bio-HDPE/20PLA piece. However, only the piece treated with MLO in combination with DCP showed an improvement in the thermomechanical response, having a value of $85.8 \pm 1.2 \mu \mathrm{m} / \mathrm{m}^{\circ} \mathrm{C}$. 
The greatest thermomechanical changes were observed at temperatures higher than 70 ${ }^{\circ} \mathrm{C}$, that is, above $\mathrm{T}_{\mathrm{g}}$ of PLA. While the neat bio-HDPE piece showed a CLTE value of $465.3 \pm 0.6 \mathrm{\mu m} / \mathrm{m}^{\circ} \mathrm{C}$, the addition of PLA positively reduced this values up to $342.1 \pm$ $0.96 \mu \mathrm{m} / \mathrm{m}^{\circ} \mathrm{C}$, for the piece containing $20 \mathrm{wt} \%$ PLA. This implies a lower expansion with temperature, thus improving the service conditions of the injection-molded pieces. Although the addition of all compatibilizers increased the CLTE values of the bio-HDPE/20 PLA pieces, the combined use of MLO and DCP again successfully kept this value in the same order of magnitude, that is, $359.4 \pm 1.1 \mu \mathrm{m} / \mathrm{m}^{\circ} \mathrm{C}$. It is worthy to mention the high increase observed for the MLO-treated piece, reaching a CLTE value of $525.1 \pm 1.0 \mu \mathrm{m} / \mathrm{m}^{\circ} \mathrm{C}$. This further supports the plasticization produced in the dispersed PLA phase, as described in detail in our previous studies. ${ }^{4,6,61}$

\section{CONCLUSIONS}

The present study describes the preparation by melt compounding and subsequent injection molding of binary blend pieces of bio-HDPE/PLA, at PLA contents from 5 wt $\%$ to $20 \mathrm{wt} \%$, with the aim to develop a cost-effective and fully renewable plastic articles with high mechanical strength and rigidity but with still sufficient mechanical ductility. Whereas the incorporation of PLA into bio-HDPE resulted in an increase of the mechanical strength of the pieces, their toughness significantly decreased with the PLA content. The reduction observed in the ductile properties suggested a poor stress transfer between the two biopolymer phases, due their lack of compatibility, in which the dispersed PLA phase potentially acted as a stress concentrator in the bio-HDPE matrix favoring the piece rupture. The low of miscibility, at the here-studied mixing ratios, between both biopolymers was confirmed by morphological analysis of the fracture surfaces of pieces after the impact tests. In particular, it was observed that PLA remained mainly incorporated into the bio-HDPE matrix as a dispersed phase in the form of micro-sized spherical domains or droplets to generate an "island-and-sea" morphology. The thermal and thermomechanical studies carried out on the biopolymer pieces further confirmed the poor compatibility or absence of miscibility between bio-HDPE and PLA.

In order to increase miscibility and, thus, the mechanical and thermal performance of the pieces, different reactive compatibilizers were tested on the blend pieces of bioHDPE with $20 \mathrm{wt} \%$ PLA, that is, bio-HDPE/20PLA. In particular, it was explored the use of a grafted polymer, that is, PE- $g$-MA, a copolymer, that is, PE-co-GMA, a multifunctionalized vegetable oils, that is, MLO, and a combination of MLO with a peroxide, that is, DCP. The obtained results showed that the addition of either PE- $g$-MA or PE-coGMA induced a low improvement on the physical performance of the pieces since these additives were not able to interact with both biopolymers and the binary blend pieces still presented a marked phase separation. In relation to MLO, it was observed that the multi-functionalized vegetable oil was mainly solubilized in the dispersed PLA phase, which became highly plasticized so that it induced an overall enhancement of the ductile properties in the binary blend pieces. Interestingly, the optimal performance was attained for the binary blend piece simultaneously treated with MLO and $\mathrm{DCP}$, which presented the highest modulus, that is, $582 \mathrm{MPa}$, and also a relatively 
578 high value of impact strength, that is, $3.71 \mathrm{~kJ} / \mathrm{m}^{2}$. The fracture surface of the bio579 HDPE/20PLA piece processed with MLO and DCP revealed the presence of a 580 continuous structure where the dispersed MLO-containing PLA droplets were mostly 581 no longer discerned and the bio-HDPE matrix fully covered the enclosed PLA regions. 582 This morphological change was attributed to the cross-linking effect of DCP, which 583 resulted in a more polymer interconnected network. The latter effect was related to the 584 formation of macroradicals of each biopolymer that, thereafter, led to the in situ 585 formation of bio-HDPE-co-PLA copolymers and also to the development of a partially 586 cross-linked network in the blend. Furthermore, the combined use of both 587 compatibilizers yielded a thermal stability increase of up to $14{ }^{\circ} \mathrm{C}$.

589 It can be concluded that the combination of multi-functionalizes vegetable oils and 590 peroxides represents an attractive strategy to enhance the miscibility between green 591 polyolefins and biopolyesters and it can potentially contribute to the development of 592 sustainable polymer technologies. The here-obtained injection-molded pieces made of 593 bio-HDPE with up to $20 \mathrm{wt} \%$ PLA present higher mechanical resistance and similar 594 impact strength than those of neat bio-HDPE. These pieces, which are fully bio-based, 595 can be then regarded as great candidates for being use in sustainable rigid packaging. 596 Potential uses include, for instance, rigid packaging articles such as food trays and lids,

597 kitchen utensils and countertops, and storage containers, or surfaces such as cutting 598 boards.

599

600

\section{Acknowledgements}

601 This research was funded by the EU H2020 project YPACK (reference number 773872) 602 and by the Ministry of Science, Innovation, and Universities (MICIU, project numbers 603 MAT2017-84909-C2-2-R and AGL2015-63855-C2-1-R). Quiles-Carrillo and Torres-Giner 604 are recipients of a FPU grant (FPU15/03812) from the Spanish Ministry of Education, 605 Culture, and Sports (MECD) and a Juan de la Cierva contract (IJCI-2016-29675) from 606 the MICIU, respectively. 
608 1. Tahir, N.; Bhatti, H. N.; Iqbal, M.; Noreen, S., Int. J. Biol. Macromol. 94, 2102017.

2. Imre, B.; Pukánszky, B., Eur. Polym. J. 49, 12152013.

3. Quiles-Carrillo, L.; Montanes, N.; Lagaron, J.; Balart, R.; Torres-Giner, S., Polym. Int. 67, 13412018.

4. Quiles-Carrillo, L.; Blanes-Martínez, M.; Montanes, N.; Fenollar, O.; Torres-Giner, S.; Balart, R., Eur. Polym. J. 98, 4022018.

5. Yu, L.; Dean, K.; Li, L., Prog. Polym. Sci. 31, 5762006.

6. Quiles-Carrillo, L.; Pineiro, F.; Jorda-Vilaplana, A.; Montanes, N.; Torres-Giner, S., Materials 11, 21382018.

7. Kumar, S.; Panda, A. K.; Singh, R., Resour. Conserv. Recy. 55, 8932011.

8. Biresaw, G.; Carriere, C., J. Polym. Sci. A2. 40, 22482002.

9. Li, N.; Li, Y.; Liu, S., J. Mater. Process. Tech. 238, 2182016.

10. Lasprilla, A. J.; Martinez, G. A.; Lunelli, B. H.; Jardini, A. L.; Maciel Filho, R., Biotechnol. Adv. 30, 3212012.

11. da Silva, D.; Kaduri, M.; Poley, M.; Adir, O.; Krinsky, N.; Shainsky-Roitman, J.; Schroeder, A., Chem. Eng. J.2018.

12. Oksman, K.; Skrifvars, M.; Selin, J.-F., Compos. Sci. Technol. 63, 13172003.

13. Auras, R.; Harte, B.; Selke, S., Macromolecular Bioscience 4, 8352004.

14. Agrawal, A.; Saran, A. D.; Rath, S. S.; Khanna, A., Polymer 45, 86032004.

15. Camacho, J.; Diez, E.; Diaz, I.; Ovejero, G., Polym. Int. 66, 10132017.

16. Ferri, J. M.; Samper, M. D.; Garcia-Sanoguera, D.; Reig, M. J.; Fenollar, O.; Balart, R., J. Mater. Sci. 51, 53562016.

17. Patricia Arrieta, M.; Dolores Samper, M.; Aldas, M.; Lopez, J., Materials 102017.

18. Ying-Chen, Z.; Hong-Yan, W.; Yi-Ping, Q., Bioresource. Technol. 101, 79442010.

19. Garcia, D.; Balart, R.; Sanchez, L.; Lopez, J., Polym. Eng. Sci. 47, 7892007.

20. Afshari, M.; Kotek, R.; Kish, M. H.; Dast, H. N.; Gupta, B. S., Polymer 43, 13312002.

21. Palabiyik, M.; Bahadur, S., Wear. 246, 1492000.

22. Muthuraj, R.; Misra, M.; Mohanty, A. K., J. Appl. Polym. Sci., 457262017.

23. Macosko, C.; Guegan, P.; Khandpur, A. K.; Nakayama, A.; Marechal, P.; Inoue, T., Macromolecules 29, 55901996.

24. Wang, Y.; Hillmyer, M. A., J. Polym. Sci. A1. 39, 27552001.

25. Nehra, R.; Maiti, S.; Jacob, J., Polym. Advan. Technol. 29, 2342018.

26. Arostegui, A.; Nazabal, J., J. Polym. Sci. A2. 41, 22362003.

27. Li, Z.; Tan, B. H.; Lin, T.; He, C., Prog. Polym. Sci. 62, 222016.

28. Torres-Giner, S.; Montanes, N.; Boronat, T.; Quiles-Carrillo, L.; Balart, R., Eur. Polym. J. 84, 6932016.

29. Quiles-Carillo, L.; Montanes, N.; Lagaron, J. M.; Balart, R.; Torres-Giner, S., J. Polym. Environ. DOI: 10.1007/s10924-018-1324-2.2018.

30. Zeng, J.-B.; Li, K.-A.; Du, A.-K., Rsc. Adv. 5, 325462015.

31. Yang, L.; Huang, J.; Lu, X.; Jia, S.; Zhang, H.; Jin, G.; Qu, J., J. Appl. Polym. Sci. 1322015.

32. Carbonell-Verdu, A.; Samper, M. D.; Garcia-Garcia, D.; Sanchez-Nacher, L.; Balart, R., Ind. Crops. Prod 104, 2782017.

33. Garcia-Campo, M. J.; Quiles-Carrillo, L.; Masia, J.; Reig-Pérez, M. J.; Montanes, N.; Balart, R., Materials 10, 13392017.

34. Ferri, J.; Garcia-Garcia, D.; Sánchez-Nacher, L.; Fenollar, O.; Balart, R., Carbohyd. Polym. 147, 602016.

35. Ferri, J. M.; Garcia-Garcia, D.; Montanes, N.; Fenollar, O.; Balart, R., Polym. Int. 66, 8822017. 
36. Miao, S.; Wang, P.; Su, Z.; Zhang, S., Acta. Mater. 10, 16922014.

37. Chen, G.; Li, S.; Jiao, F.; Yuan, Q., Catal. Today. 125, 1112007.

38. Babu, R. P.; O'connor, K.; Seeram, R., Progress in Biomaterials 2, 82013.

39. Torres-Giner, S.; Torres, A.; Ferrándiz, M.; Fombuena, V.; Balart, R., J. Food. Safety 372017.

40. Abdolrasouli, M. H.; Sadeghi, G. M. M.; Nazockdast, H.; Babaei, A., Polym-Plast. Technol. 53, 14172014.

41. Abdolrasouli, M. H.; Nazockdast, H.; Sadeghi, G. M. M.; Kaschta, J., J. Appl. Polym. Sci. 1322015.

42. Madhu, G.; Bhunia, H.; Bajpai, P. K.; Chaudhary, V., J. Polym. Eng. 34, 8132014.

43. Betron, C.; Cassagnau, P.; Bounor-Legare, V., Mater. Chem. Phys. 211, 3612018.

44. Minhaz-Ul Haque, M.; Herrera, N.; Geng, S.; Oksman, K., J. Appl. Polym. Sci. 1352018.

45. Pourshooshtar, R.; Ahmadi, Z.; Taromi, F. A., Iran. Polym. J 27, 3292018.

46. Zhou, L.; He, H.; Li, M.-c.; Huang, S.; Mei, C.; Wu, Q., Ind. Crops. Prod 112, 449 2018.

47. Yang, S.-1.; Wu, Z.-H.; Yang, W.; Yang, M.-B., Polym. Test. 27, 9572008.

48. Garcia-Garcia, D.; Rayón, E.; Carbonell-Verdu, A.; Lopez-Martinez, J.; Balart, R., Eur. Polym. J. 86, 412017.

49. Ma, P.; Hristova-Bogaerds, D. G.; Lemstra, P. J.; Zhang, Y.; Wang, S., Macromol. Mater. Eng. 297, 4022012.

50. Utracki, L. A., Can. J. Chem. Eng. 80, 10082002.

51. Wang, Q.; Qi, R.; Shen, Y.; Liu, Q.; Zhou, C., J. Appl. Polym. Sci. 106, 32202007.

52. Quiroz-Castillo, J.; Rodríguez-Félix, D.; Grijalva-Monteverde, H.; del CastilloCastro, T.; Plascencia-Jatomea, M.; Rodríguez-Félix, F.; Herrera-Franco, P., Carbohyd. Polym. 101, 10942014.

53. Ma, P.; Cai, X.; Zhang, Y.; Wang, S.; Dong, W.; Chen, M.; Lemstra, P., Polym. Degrad. Stabil. 102, 1452014.

54. Li, Y.; Hu, G.; Wang, B., J. Appl. Polym. Sci. 118, 21262010.

55. Yoo, T. W.; Yoon, H. G.; Choi, S. J.; Kim, M. S.; Kim, Y. H.; Kim, W. N., Macromol. Res. 18, 5832010.

56. Lai, S.-M.; Lan, Y.-C.; Wu, W.-L.; Wang, Y.-J., J. Appl. Polym. Sci. 1322015.

57. Montanes, N.; Garcia-Sanoguera, D.; Segui, V.; Fenollar, O.; Boronat, T., J. Polym. Environ. 26, 12182018.

58. García-Campo, M. J.; Boronat, T.; Quiles-Carrillo, L.; Balart, R.; Montanes, N., Polymers-Basel 10, 32017.

59. Huang, Y.; Zhang, C.; Pan, Y.; Wang, W.; Jiang, L.; Dan, Y., J. Polym. Environ. 21, 3752013.

60. Wang, N.; Yu, J.; Ma, X., Polym. Int. 56, 14402007.

61. Ferri, J. M.; Garcia-Garcia, D.; Sanchez-Nacher, L.; Fenollar, O.; Balart, R., Carbohyd. Polym. 147, 602016. 
700 Figure 1. Chemical structure of the different compatibilizers used in this work.

701 Figure 2. Schematic representation of the manufacturing process of the injection702 molded pieces of bio-based high-density polyethylene (bio-HDPE)/polylactide (PLA) 703 blends.

704 Figure 3. Field emission scanning electron microscopy (FESEM) images, taken at 1000×, 705 of the surface fractures of the injection-molded pieces of: a) Neat bio-based high706 density polyethylene (bio-HDPE); b) Bio-HDPE/5 polylactide (PLA); c) Bio707 HDPE/10PLA; d) Bio-HDPE/15PLA; e) Bio-HDPE/20PLA; f) Bio-HDPE/20PLA + 708 polyethylene-grafted maleic anhydride (PE-g-MA); g) Bio-HDPE/20PLA + 709 poly(ethylene-co-glycidyl methacrylate) (PE-co-GMA); h) Bio-HDPE/20PLA + 710 maleinized linseed oil (MLO); i) Bio-HDPE/20PLA+MLO + dicumyl peroxide (DCP). 711 Scale markers of $20 \mu \mathrm{m}$.

712 Figure 4. Differential scanning calorimetry (DSC) curves of the injection-molded pieces 713 of bio-based high-density polyethylene (bio-HDPE) blended with different percentages 714 of polylactide (PLA) and compatibilized with polyethylene-grafted maleic anhydride 715 (PE-g-MA), poly(ethylene-co-glycidyl methacrylate) (PE-co-GMA), maleinized linseed 716 oil (MLO), and dicumyl peroxide (DCP).

717 Figure 5. Thermogravimetric analysis (TGA) curves of the injection-molded pieces of 718 bio-based high-density polyethylene (bio-HDPE) blended with different percentages of 719 polylactide (PLA) and compatibilized with polyethylene-grafted maleic anhydride (PE720 g-MA), poly(ethylene-co-glycidyl methacrylate) (PE-co-GMA), maleinized linseed oil 721 (MLO), and dicumyl peroxide (DCP): a) Weight loss and b) First derivate.

722 Figure 6. Dynamical mechanical thermal analysis (DMTA) curves of the injectionmolded pieces of bio-based high-density polyethylene (bio-HDPE) blended with different percentages of polylactide (PLA) and compatibilized with polyethylenegrafted maleic anhydride (PE-g-MA), poly(ethylene-co-glycidyl methacrylate) (PE-coGMA), maleinized linseed oil (MLO), and dicumyl peroxide (DCP): a) Storage modulus $\left(G^{\prime}\right)$ and $\left.b\right)$ damping factor $(\tan \partial)$. 
730 Table 1. Summary of compositions according to the weight content (wt\%) of bio-based 731 high-density polyethylene (bio-HDPE) and polylactide (PLA) in which polyethylene732 grafted maleic anhydride (PE-g-MA), poly(ethylene-co-glycidyl methacrylate) (PE-co733 GMA), maleinized linseed oil (MLO), and dicumyl peroxide (DCP) were added as 734 parts per hundred resin (phr) of biopolymer blend.

735

\begin{tabular}{|c|c|c|c|c|c|c|}
\hline Sample & $\begin{array}{l}\text { Bio-HDPE } \\
(w t \%)\end{array}$ & $\begin{array}{c}\text { PLA } \\
\left(w t^{0} \%\right)\end{array}$ & $\begin{array}{c}\text { PE-g-MA } \\
\text { (phr) }\end{array}$ & $\begin{array}{l}\text { PE-co-GMA } \\
\text { (phr) }\end{array}$ & $\begin{array}{l}\text { MLO } \\
\text { (phr) }\end{array}$ & $\begin{array}{l}\text { DCP } \\
\text { (phr) }\end{array}$ \\
\hline Bio-HDPE & 100 & 0 & 0 & 0 & 0 & 0 \\
\hline Bio-HDPE/5PLA & 95 & 5 & 0 & 0 & 0 & 0 \\
\hline Bio-HDPE/10PLA & 90 & 10 & 0 & 0 & 0 & 0 \\
\hline Bio-HDPE/15PLA & 85 & 15 & 0 & 0 & 0 & 0 \\
\hline Bio-HDPE/20PLA & 80 & 20 & 0 & 0 & 0 & 0 \\
\hline $\begin{array}{l}\text { Bio-HDPE/20PLA+PE-g- } \\
\text { MA }\end{array}$ & 80 & 20 & 3 & 0 & 0 & 0 \\
\hline $\begin{array}{l}\text { Bio-HDPE/20PLA+PE-co- } \\
\text { GMA }\end{array}$ & 80 & 20 & 0 & 3 & 0 & 0 \\
\hline Bio-HDPE/20PLA+MLO & 80 & 20 & 0 & 0 & 5 & 0 \\
\hline $\begin{array}{l}\text { Bio- } \\
\text { HDPE/20PLA+MLO+DCP }\end{array}$ & 80 & 20 & 0 & 0 & 5 & 1 \\
\hline
\end{tabular}


Table 2. Mechanical properties in terms of tensile modulus ( $\left.E_{\text {tensile }}\right)$, maximum tensile strength $\left(\sigma_{\max }\right)$, elongation at break $\left(\varepsilon_{\mathrm{b}}\right)$, Shore D hardness, and impact strength of the injection-molded pieces of bio-based high-density polyethylene (bio-HDPE) blended with different percentages of polylactide (PLA) and compatibilized with polyethylenegrafted maleic anhydride (PE-g-MA), poly(ethylene-co-glycidyl methacrylate) (PE-coGMA), maleinized linseed oil (MLO), and dicumyl peroxide (DCP).

\begin{tabular}{|c|c|c|c|c|c|}
\hline Sample & $\mathrm{E}_{\text {tensile }}(\mathrm{MPa})$ & $\sigma_{\max }(\mathrm{MPa})$ & $\varepsilon_{\mathrm{b}}(\%)$ & $\begin{array}{c}\text { Shore D } \\
\text { hardness }\end{array}$ & $\begin{array}{c}\text { Impact strength } \\
\left(\mathrm{kJ} / \mathrm{m}^{2}\right)\end{array}$ \\
\hline Bio-HDPE & $408.4 \pm 16.6$ & $21.6 \pm 0.4$ & $545.2 \pm 56,1$ & $61.8 \pm 0.8$ & $3.77 \pm 0.2$ \\
\hline Bio-HDPE/5PLA & $492.9 \pm 11.1$ & $21.7 \pm 0.2$ & $499.0 \pm 74.5$ & $62.0 \pm 0.7$ & $2.83 \pm 0.2$ \\
\hline Bio-HDPE/10PLA & $500.0 \pm 9.10$ & $21.5 \pm 0.2$ & $253.2 \pm 35.8$ & $63.2 \pm 0.8$ & $1.88 \pm 0.2$ \\
\hline Bio-HDPE/15PLA & $538.6 \pm 6.34$ & $22.2 \pm 0.1$ & $122.4 \pm 6.73$ & $66.2 \pm 0.8$ & $1.76 \pm 0.2$ \\
\hline Bio-HDPE/20PLA & $563.0 \pm 10.3$ & $23.2 \pm 0.3$ & $54.0 \pm 6.09$ & $67.4 \pm 1.1$ & $1.70 \pm 0.2$ \\
\hline Bio-HDPE/20PLA+PE-g-MA & $568.1 \pm 8.84$ & $22.7 \pm 0.2$ & $57.6 \pm 4.33$ & $68.0 \pm 0.7$ & $1.57 \pm 0.2$ \\
\hline Bio-HDPE/20PLA+PE-co-GMA & $570.1 \pm 6.38$ & $22.1 \pm 0.1$ & $34.4 \pm 4.28$ & $67.5 \pm 0.9$ & $2.01 \pm 0.3$ \\
\hline Bio-HDPE/20PLA+MLO & $496.1 \pm 17.4$ & $18.9 \pm 0.2$ & $50.5 \pm 2.71$ & $58.8 \pm 1.5$ & $3.96 \pm 0.3$ \\
\hline Bio-HDPE/20PLA+MLO+DCP & $582.0 \pm 6.07$ & $22.0 \pm 0.2$ & $23.2 \pm 1.16$ & $65.8 \pm 0.8$ & $3.71 \pm 0.5$ \\
\hline
\end{tabular}


Table 3. Thermal properties in terms of onset degradation temperature $\left(T_{5 \%}\right)$, degradation temperature $\left(\mathrm{T}_{\mathrm{deg}}\right)$, and residual mass at $700{ }^{\circ} \mathrm{C}$ of the injection-molded pieces of bio-based high-density polyethylene (bio-HDPE) blended with different percentages of polylactide (PLA) and compatibilized with polyethylene-grafted maleic anhydride (PE-g-MA), poly(ethylene-co-glycidyl methacrylate) (PE-co-GMA), maleinized linseed oil (MLO), and dicumyl peroxide (DCP).

\begin{tabular}{|l|c|c|c|c|}
\hline Sample & $\mathbf{T}_{5 \%}\left({ }^{\circ} \mathrm{C}\right)$ & $\mathbf{T}_{\operatorname{deg} 1}\left({ }^{\circ} \mathrm{C}\right)$ & $\mathbf{T}_{\operatorname{deg} 2}\left({ }^{\circ} \mathrm{C}\right)$ & Residual mass (\%) \\
\hline Bio-HDPE & $312.5 \pm 1.7$ & - & $455.2 \pm 1.5$ & $0.2 \pm 0.3$ \\
\hline Bio-HDPE/5PLA & $324.1 \pm 1.4$ & $359.5 \pm 1.6$ & $466.5 \pm 1.8$ & $0.3 \pm 0.2$ \\
\hline Bio-HDPE/10PLA & $327.2 \pm 1.8$ & $356.2 \pm 1.8$ & $470.9 \pm 1.5$ & $0.2 \pm 0.3$ \\
\hline Bio-HDPE/15PLA & $328.9 \pm 1.5$ & $355.2 \pm 1.7$ & $466.5 \pm 1.6$ & $0.3 \pm 0.2$ \\
\hline Bio-HDPE/20PLA & & & & \\
\hline Bio-HDPE/20PLA+PE-g-MA & $324.9 \pm 1.6$ & $358.1 \pm 2.0$ & $465.1 \pm 1.9$ & $0.1 \pm 0.1$ \\
\hline Bio-HDPE/20PLA+PE-co-GMA & $327.3 \pm 1.7$ & $356.6 \pm 1.7$ & $445.2 \pm 1.8$ & $0.4 \pm 0.1$ \\
\hline Bio-HDPE/20PLA+MLO & $332.9 \pm 2.1$ & $360.9 \pm 2.1$ & $453.7 \pm 1.9$ & $0.3 \pm 0.2$ \\
\hline Bio-HDPE/20PLA+MLO+DCP & $338.9 \pm 1.4$ & $365.1 \pm 1.9$ & $465.1 \pm 2.0$ & $0.5 \pm 0.3$ \\
\hline
\end{tabular}


Table 4. Coefficients of linear thermal expansion (CLTE) of the injection-molded pieces of bio-based high-density polyethylene (bio-HDPE) blended with different percentages of polylactide (PLA) and compatibilized with polyethylene-grafted maleic anhydride (PE-g-MA), poly(ethylene-co-glycidyl methacrylate) (PE-co-GMA), maleinized linseed oil (MLO), and dicumyl peroxide (DCP).

\begin{tabular}{|c|c|c|c|}
\hline \multirow[t]{2}{*}{ Sample } & \multicolumn{3}{|c|}{$\operatorname{CLTE}\left(\mu \mathrm{m} / \mathrm{m}^{\circ} \mathrm{C}\right)$} \\
\hline & $\mathrm{T}<-110{ }^{\circ} \mathrm{C}$ & $-110^{\circ} \mathrm{C} \geq \mathrm{T} \leq 70^{\circ} \mathrm{C}$ & $\mathrm{T}>70^{\circ} \mathrm{C}$ \\
\hline Bio-HDPE & $112.7 \pm 0.3$ & $134.0 \pm 0.4$ & $465.3 \pm 0.6$ \\
\hline Bio-HDPE/5PLA & $110.7 \pm 0.8$ & $103.9 \pm 0.6$ & $457.2 \pm 0.9$ \\
\hline Bio-HDPE/10PLA & $107.3 \pm 1.3$ & $110.2 \pm 0.9$ & $408.9 \pm 0.5$ \\
\hline Bio-HDPE/15PLA & $109.2 \pm 0.9$ & $98.2 \pm 0.7$ & $408.7 \pm 0.6$ \\
\hline Bio-HDPE/20PLA & $107.6 \pm 1.2$ & $94.3 \pm 1.1$ & $342.1 \pm 0.9$ \\
\hline Bio-HDPE/20PLA+PE- $g$-MA & $109.5 \pm 0.9$ & $101.7 \pm 0.8$ & $356.8 \pm 1.5$ \\
\hline Bio-HDPE/20PLA+PE-co-GMA & $101.2 \pm 1.1$ & $101.3 \pm 0.9$ & $499.2 \pm 1.1$ \\
\hline Bio-HDPE/20PLA+MLO & $99.6 \pm 0.9$ & $102.1 \pm 1.3$ & $525.1 \pm 1.0$ \\
\hline Bio-HDPE/20PLA+MLO+DCP & $90.6 \pm 1.3$ & $85.8 \pm 1.2$ & $359.4 \pm 1.1$ \\
\hline
\end{tabular}

